\title{
FALLING ASLEEP AT THE WHEEL AMONG ITALIAN PROFESSIONAL DRIVERS (PDS): RESULTS FROM THE HIRIS PD STUDY
}

\author{
${ }^{1}$ Medical Emergency Service, A.S.L. CN1, Cuneo, Italy \\ ${ }^{2}$ Occupational Safety and Health, Medical Services, Se.M. s.r.l., Cuneo, Italy \\ ${ }^{3}$ Emergency Department, Santa Croce e Carle Hospital, Cuneo, Italy \\ ${ }^{4}$ Cardiovascular Rehabilitation, Heart Failure Unit, A.S.L. CN1, Fossano, Italy \\ ${ }^{5}$ Technical Service, A.S.L. CN1, Cuneo, Italy
}

GIAN LUCA ROSSO ${ }^{1,2}$, MASSIMO PEROTTO ${ }^{3}$, MAURO FEOLA ${ }^{4}$, and MICHELE CARAMELLA ${ }^{5}$

\begin{abstract}
Objectives: A high percentage of professional drivers (PDs) often report feeling fatigue during their work, and falling asleep at the wheel (FAW) is a major contributing factor to the occurrence of near-miss or actual accidents. The aim of this study is to evaluate the prevalence of FAW among Italian PDs and the effect of fatigue on this occurrence (corrected for the main predictive factors already known). Material and Methods: We performed a cross-sectional questionnaire survey. Data from PDs $(\mathrm{N}=497)$ were used for analyses. Logistic regression analyses were performed to assess the association of reported sudden-onset sleep at the wheel with working conditions and general lifestyle factors. Results: Forty-one percent of the interviewees experienced at least 1 episode per month of sudden-onset sleep at the wheel (4.7\% per week). Predictive factors of self-reported FAW were: age $>55$ years old (odds ratio $(\mathrm{OR})=4.91$, confidence interval $(\mathrm{CI}): 1.79-13.50$, $p<0.01$ ), traveling more than 40 thousand miles per year ( $\mathrm{OR}=1.86,95 \% \mathrm{CI}: 1.08-3.22, \mathrm{p}<0.05)$, body mass index $\geq 30$ $(\mathrm{OR}=2.16,95 \% \mathrm{CI}: 1.01-4.64, \mathrm{p}<0.05)$ and Chalder Fatigue Questionnaire score $>22$ (OR = 3.93, 95\% CI: 1.90-8.14, $\mathrm{p}<0.01)$. Conclusions: There are different work and human factors underlying FAW among PDs. The Chalder Fatigue Questionnaire might be useful in measuring fatigue in this group and in detecting PDs at high risk of experiencing FAW.
\end{abstract}

Key words:

Risk factors, Fatigue, Falling asleep at the wheel, Professional drivers, Road safety, Driver's health

\section{INTRODUCTION}

Falling asleep at the wheel (FAW) is a major contributing factor to the occurrence of near-miss or actual accidents [1-3]. In this regard, an Israeli study stressed the fact that self-reported fatigue and FAW occurred frequently in professional drivers (PDs) who do not experience problems in sleep quality, pointing to the importance of working conditions. Some of the reasons for work-related fatigue among PDs are: long working shifts, poor working conditions, chronic illness, lack of sleep, sleep disorders and the incapability to choose the time of breaks [4,5].

Italian and international legislation regulating the amount of driving PDs perform over the course of a day and week does exist, but these rules are often not observed [6,7]. Measuring the prevalence of fatigue and FAW is a tough task. Self-assessment (with a simple query) is an insensitive indicator of fatigue and, to our knowledge, the severity

Received: April 17, 2014. Accepted: July 18, 2014.

Corresponding author: G.L. Rosso, Via Torre Allera, 55-12100 Cuneo, Italy (e-mail: glrosso77@gmail.com). 
of fatigue among PDs has never been measured using the Chalder Fatigue Score (CFS).

Knowing that prevention of sudden-onset sleep at the wheel among PDs is a priority in the workplace, we must look for more important work and human factors leading to this event and evaluate if and how the measure of fatigue can be related to this event. It is likely that fatigue measured with a scale which considers a range of factors reflecting perceived poor physical and psychological functioning as well as physical tiredness - could be associated with FAW (even when adjusted for important predictors). Moreover, we investigated the contribution of the most important work-related factors (hours driving, miles driving, seniority, etc.) and the role of individual factors in relation to the reported fatigue among PDs (adjusted for some work-related potential mediators). It is well known that there is a need to educate at least some drivers about the fact that extreme sleepiness is very likely to lead to falling asleep [8]. For this reason, our study aimed to identify some crucial and objectified factors that lead to a PD with a high risk of FAW.

This study, whose data are a part of what has been collected in the High Risk Professional Driver (HiRis PD) study, investigated the most crucial factors that lead to suddenonset sleep at the wheel among PDs, through the collection and analysis of anonymous questionnaires administered in a context totally unrelated to the usual inspections carried out by the Occupational Health Physician (OHP) or by inspectors (health officers, police officers, etc.). The main study hypotheses that we tested were: presence of a higher CFS among PDs who report FAW while driving and capability of the CFS to predict FAW.

\section{MATERIAL AND METHODS}

\section{Study design}

From 1 October 2012 to 31 May 2013 we conducted a survey using a self-administered and anonymous questionnaire during Certificate of Professional Competence $(\mathrm{CPC})$ courses for professional truck and bus drivers. Study participants were recruited on a voluntary basis from driving schools and associations across 6 towns in the province of Cuneo (an area of the Piedmont region in northern Italy). Professional drivers were asked to participate if they declared that they had been in possession of a professional driving licence $(\mathrm{C}, \mathrm{D}$ and/or $\mathrm{C}, \mathrm{D}+\mathrm{E}$ Italian categories) for more than 3 years. No identifying information on drivers or carriers was collected. Professional drivers were assured that their responses were completely anonymous. The questionnaire was administered after the coffee break of each course, and, once filled in, the PDs placed it in a closed urn. Before the administration of the questionnaire, PDs received detailed information on the purpose of the study and an explanation on how to fill in the questionnaire.

\section{Measures}

Professional drivers were asked to fill in the questionnaire which included, apart from general information (demographics, anthropometry and medical information), their driving and accident history. In particular, the main question related to this study was: "In the past 12 months, have you experienced falling asleep at the wheel when driving?" (1 - never, 2 - a few times (about once a month), 3 - often (about once a week), 4 - more than once a week).

After the beginning of the survey we decided to integrate the questionnaire with a validated questionnaire to measure the severity of fatigue. For this purpose we applied the Chalder Fatigue Questionnaire (CFQ), which has been used in several studies.

The 11-item scale was found to be reliable (Physical Fatigue: $r=0.85$; Mental Fatigue: $r=0.82$; Total Score: $r=0.89$ ) and valid. Fatigue is defined as a continuous dimension as opposed to a category. Response options include: 1 - better than usual, 2 - no more than 
usual, 3 - worse than usual, and 4 - much worse than usual. The "Likert" scoring allocates 1, 2, 3 and 4 to these answers, with scores from 11 to 44 . Higher scores indicate greater fatigue [9]. The questionnaire also included the Alcohol Use Disorders Identification Test Consumption (AUDIT C), which is a revised and shorter version of AUDIT (a gold standard of identification tests, developed by WHO, consisting of 10 alcohol identification questions) [10].

Body mass index (BMI) was calculated as weight divided by height squared and expressed as $\mathrm{kg} / \mathrm{m}^{2}$ (height and weight were self-reported). A BMI $\geq 30$ was regarded as compatible with obesity.

\section{Statistical analysis}

Descriptive statistics were used to report the prevalence of various factors. Categorical data were presented as numbers (percent), continuous data as means $(\mathrm{M}) \pm$ standard deviation (SD) for normally distributed variables. The Shapiro-Wilk test was used to evaluate whether or not the distribution of the variables was normal. The mean values of 2 groups were compared using the Student's t-test and the means of more than 2 groups were assessed using analysis of variance followed by the Bonferroni multiple-comparison test. The Pearson $\mathrm{Chi}^{2}$ test and the Fisher's exact test were used for comparing categorical variables.

We generated a dummy dependent variable indicating whether the respondent reported FAW while driving in the past year. The variables with $\mathrm{p}<0.20$ in the univariate regression analysis were employed in the multivariate regression model. Variables that showed co-linearity or low frequency were excluded from the multivariate model, whilst variables with more than 2 categories were transformed into indicator (dummy) variables. The final models for the logistic regression analysis were constructed using stepwise regression analysis to select the minimum set of predictors that significantly $(\mathrm{p} \leq 0.05)$ maximized the model. A multivariate logistic regression model was evaluated with the receiver operating characteristic (ROC) analysis. Results were considered significant if $\mathrm{p} \leq 0.05$. All statistical calculations were performed using Stata software (version 11.0 Stata Corporation, College Station, TX, USA).

\section{RESULTS}

We received responses to the questionnaire from 497 of the 508 PDs participating in CPC courses $(71.6 \%$ truck drivers, $26.3 \%$ bus drivers and $2.1 \%$ truck and bus drivers). More than $99 \%$ were male (in order to ensure anonymity, gender was not required in the questionnaire). Fifty-nine point one percent of PDs declared their company has $\leq 10$ employees. Ninety-five percent of PDs declared a maximum distance of less than 100000 miles/year and reported working less than $10 \mathrm{~h} /$ day.

Twenty-one point 4 percent declared they drink alcoholic beverages during working hours or work breaks. Fifteen percent of the participants have an AUDIT C score $\geq 5$, as previously reported in a specific article related to the HiRis PD study [11]. Of the participants $90 / 497$ (18.1\%) declared the use of medicines, the reasons including: 19/497 (3.8\%) allergies, 3/497 (0.6\%) anxiety and depression, 10/497 (2\%) diabetes, 7/497 (1.4\%) heart conditions, 60/497 (12.1\%) high blood pressure. The questionnaire was designed to be easily self-completed by PDs, therefore we decided not to discourage compilers by trying to record more information about medication.

Among the participants, 200 out of 487 (41.1\%) reported having experienced sudden-onset sleep at the wheel while driving in the past year (at least once a month).

The CFQ was compiled by only 294 PDs, while about 200 PDs completed a questionnaire that did not include the CFQ. Sixty-four out of 294 (21.8\%) totalled a score higher than 22. The mean score was not statistically 
Table 1. Main characteristics of professional drivers (PDs) in the High Risk Professional Driver (HiRis PD) study

\begin{tabular}{|c|c|c|c|c|c|c|c|}
\hline \multirow[t]{2}{*}{ Variable } & \multicolumn{4}{|c|}{ Chalder Fatigue Score (CFS) } & \multicolumn{3}{|c|}{$\begin{array}{l}\text { Experience of FAW } \\
\text { at least once a month }\end{array}$} \\
\hline & total & $\leq 22$ & $>22$ & $\mathrm{p}$ & no & yes & $\mathrm{p}$ \\
\hline PDs $[n(\%)]$ & 497 & $230(78.2)$ & $64(21.8)$ & & $287(58.9)$ & $200(41.1)$ & \\
\hline Age (years) $(\mathrm{M} \pm \mathrm{SD})$ & $43.7 \pm 9.3$ & $43 \pm 9.2$ & $45.2 \pm 9.2$ & 0.0863 & $43.7 \pm 9.2$ & $43.6 \pm 9.4$ & 0.859 \\
\hline Seniority (years) $(\mathrm{M} \pm \mathrm{SD})$ & $18.2 \pm 9.9$ & $17.2 \pm 9.5$ & $21.1 \pm 10.7$ & 0.006 & $17.7 \pm 10$ & $18.6 \pm 9.6$ & 0.351 \\
\hline Main routes $[\mathrm{n}(\%)]$ & & & & 0.041 & & & 0.003 \\
\hline national & $376(86.4)$ & $178(79.8)$ & $45(20.2)$ & & $223(60.3)$ & $147(39.7)$ & \\
\hline international & $59(13.6)$ & $19(63.3)$ & $11(36.7)$ & & $22(39.3)$ & $34(60.7)$ & \\
\hline Educational level [n (\%)] & & & & 0.311 & & & 0.262 \\
\hline elementary school & $11(2.4)$ & $4(1.8)$ & $3(4.9)$ & & $4(1.5)$ & $6(3.2)$ & \\
\hline middle school & $274(58.8)$ & $136(61.8)$ & $36(59)$ & & $155(57.6)$ & $115(61.2)$ & \\
\hline high school & $174(37.3)$ & $74(33.7)$ & $22(36.1)$ & & $104(38.7)$ & $66(35.1)$ & \\
\hline university degree & $7(1.5)$ & $6(2.7)$ & $0(0)$ & & $6(2.2)$ & $1(0.5)$ & \\
\hline $\operatorname{BMI}[\mathrm{n}(\%)]$ & & & & 0.09 & & & 0.181 \\
\hline $\operatorname{normal}(\leq 25)$ & $188(38.4)$ & $85(37.4)$ & $28(41.4)$ & & $119(42.3)$ & $66(33.3)$ & \\
\hline overweight & $219(44.8)$ & $110(48.5)$ & $24(47.8)$ & & $122(43.4)$ & $91(46)$ & \\
\hline class I obesity & $59(12.1)$ & $24(10.6)$ & $7(7.2)$ & & $28(10)$ & $30(15.2)$ & \\
\hline class II obesity & $15(3.1)$ & $8(3.5)$ & $1(2.7)$ & & $7(2.5)$ & $8(4)$ & \\
\hline class III obesity & $8(1.6)$ & $0(0)$ & $2(0.9)$ & & $5(1.8)$ & $3(1.5)$ & \\
\hline Smoking [n (\%)] & $149(35.6)$ & $64(68.1)$ & $30(31.9)$ & 0.004 & $90(54.6)$ & $75(45.4)$ & 0.175 \\
\hline $\begin{array}{l}\text { Treatment with pharmaceuticals } \\
\text { (antihypertensive, antidiabetic, } \\
\text { sedatives or other drugs) } \\
\text { [n }(\%)]\end{array}$ & & & & $<0.001$ & & & 0.494 \\
\hline none & 407 (81.9) & $196(85.2)$ & $42(65.6)$ & & $238(82.9)$ & $161(80.5)$ & \\
\hline$\geq 1$ & $80(19.1)$ & $34(14.8)$ & $22(34.4)$ & & $49(17.1)$ & $39(19.5)$ & \\
\hline Coffee (cups) $(\mathrm{M} \pm \mathrm{SD})$ & $3.1 \pm 2.1$ & $3.1 \pm 1.8$ & $3.6 \pm 3.1$ & 0.279 & $3 \pm 1.8$ & $3.4 \pm 2.6$ & 0.117 \\
\hline $\begin{array}{l}\text { Driven distance } \\
\quad(\text { miles/year×1000) }(\mathrm{M} \pm \mathrm{SD})\end{array}$ & $46.9 \pm 39$ & $44.3 \pm 31.7$ & $51 \pm 52.9$ & 0.412 & $41.7 \pm 33.5$ & $54 \pm 45.5$ & 0.022 \\
\hline $\begin{array}{l}\text { Time spent driving (h/day) } \\
(\mathrm{M} \pm \mathrm{SD})\end{array}$ & $6.8 \pm 2.6$ & $6.9 \pm 2.5$ & $6.7 \pm 2.9$ & 0.736 & $6.4 \pm 2.6$ & $7.3 \pm 2.5$ & 0.008 \\
\hline
\end{tabular}

M - mean; SD - standard deviation; BMI - body mass index; FAW - falling asleep at the wheel.

different among PDs who drive more than 8 h per day or more than 40 thousand miles per year compared with those who drive fewer hours per day and fewer miles per year. No differences in CFS between the obese and nonobese groups were detected (19.6 vs. 20, respectively, $\mathrm{p}=$ not significant $)$ (Table 1$)$. 
Table 2. Univariate and multivariate linear regression analysis and the final model of the linear regression for CFS levels in PDs

\begin{tabular}{|c|c|c|c|c|c|c|c|}
\hline \multirow[t]{2}{*}{ Variable } & \multicolumn{2}{|c|}{ Univariate analysis } & \multicolumn{4}{|c|}{$\begin{array}{c}\text { Multivariate analysis } \\
\text { final model (model } \mathrm{R}^{2}=0.086 \text { ) }\end{array}$} & \multirow[t]{2}{*}{ VIF } \\
\hline & $\beta$ & $\mathrm{p}$ & $\beta$ & SD & $95 \% \mathrm{CI}$ & $\mathrm{p}$ & \\
\hline Seniority & 0.071 & 0.012 & 0.071 & 0.033 & $0.005-0.138$ & 0.035 & 1.07 \\
\hline Medication intake & 2.480 & $<0.000$ & 2.014 & 0.836 & $0.362-3.664$ & 0.017 & 1.04 \\
\hline Smoking & 1.073 & 0.058 & 1.955 & 0.645 & $0.682-3.227$ & 0.003 & 1.04 \\
\hline Time spent driving & -0.198 & 0.062 & -0.350 & 0.140 & $-0.627-0.073$ & 0.014 & 1.35 \\
\hline Driving distance & 0.002 & 0.825 & 0.006 & 0.010 & $-0.013-0.026$ & 0.534 & 1.32 \\
\hline Age & 0.042 & 0.141 & & & & & \\
\hline
\end{tabular}

$\beta$ - standardized beta coefficient; $\mathrm{R}^{2}$ - coefficient of determination; CI - confidence interval; VIF - variance inflation factor.

Other abbreviations as in Table 1.

In the univariate linear regression analysis, CFS levels were significantly related to seniority, hours spent at the wheel, medication intake, and smoking. The effects of age, dietary habits and drinking behaviors on the CFS were insignificant. By performing a multiple linear regression analysis using CFS as a dependent variable, the effect of seniority $(\beta=0.071, p=0.015)$ was found to be significant (adjusted for medication intake, smoking, hours spent at the wheel and driving distance) and its coefficient to be positive, indicating that the greater the seniority, the higher the CFS (data shown in Table 2).

This final model explained $8.66 \%$ (adjusted $\mathrm{R}^{2}$ ) of the CFS variability. The CFS was associated with FAW (unadjusted odd ratios $(\mathrm{OR})=1.07 ; 95 \%$ confidence interval (95\% CI): 1.02-1.13, $\mathrm{p}<0.01$ ) (to illustrate this point, the CFS is presented in Figure 1, divided on the basis of PDs' experience of sudden-onset sleep at the wheel). Based on these findings, a CFS higher than 22 was associated with an increased risk of FAW while driving of OR $=3.25$ (unadjusted; 95\% CI: 1.8-5.8, $\mathrm{p}<0.001)$ and an AUDIT C score $\geq 5$ was associated with an increased risk of FAW while driving of $\mathrm{OR}=2.29$ (unadjusted; $95 \% \mathrm{CI}$ : 1.1-4.6, $\mathrm{p}<0.01)$. The association between CFS $(>22)$ and FAW while driving, adjusted for potential confounders and mediators, is reported in Table 3 .

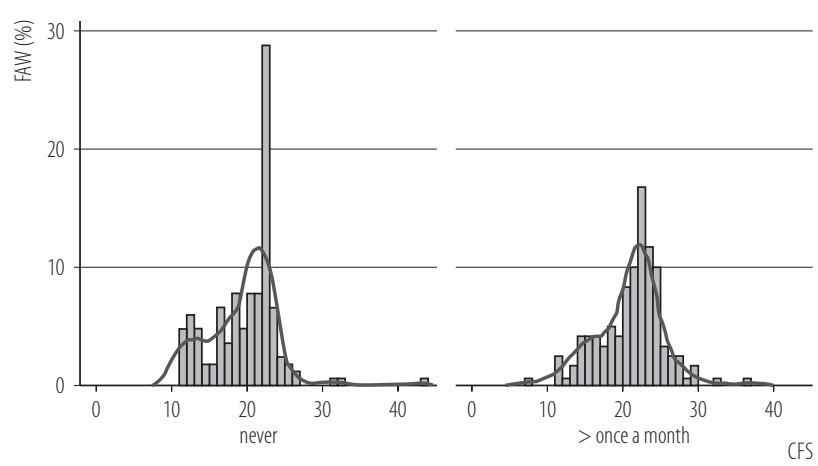

Professional drivers who recalled experiencing sudden-onset sleep at the wheel while driving (at least once a month) have a higher CFS than those who did not experience sleepiness.

Fig. 1. Correlation between falling asleep at the wheel (FAW) and Chalder Fatigue Score (CFS)

Predictive factors for sudden-onset sleep at the wheel were: age $>55$ years old $(\mathrm{OR}=4.91,95 \%$ CI: $1.79-13.50$, $\mathrm{p}<0.01)$, traveling more than 40 thousand miles per year $(\mathrm{OR}=1.86,95 \% \mathrm{CI}=1.08-3.22, \mathrm{p}<0.05), \mathrm{BMI} \geq 30$ $(\mathrm{OR}=2.16,95 \% \mathrm{CI}=1.01-4.64, \mathrm{p}<0.05), \mathrm{CFS}>22$ (adjusted OR $=3.93,95 \%$ CI: 1.90-8.14, $\mathrm{p}<0.001$ ). These results are summarized in Figure 2.

Non-significant differences in coffee consumption or smoking habits were detected among those who declared episodes of sudden-onset sleep at the wheel and those who did not. 
Table 3. Multivariate analysis testing the association between CFS and FAW while driving and adding potential confounders and mediators

\begin{tabular}{|c|c|c|c|c|c|c|c|c|}
\hline \multirow[t]{2}{*}{ Variable } & \multicolumn{2}{|r|}{ FAW } & \multicolumn{2}{|c|}{$\begin{array}{c}\text { FAW } \\
\text { adjusted for potential } \\
\text { confounders }\end{array}$} & \multicolumn{2}{|c|}{$\begin{array}{c}\text { FAW } \\
\text { adjusted for } \\
\text { driven distance } \\
\text { (a potential mediator) }\end{array}$} & \multicolumn{2}{|c|}{$\begin{array}{c}\text { FAW } \\
\text { adjusted for time } \\
\text { spent driving } \\
\text { (a potential mediator) }\end{array}$} \\
\hline & OR & $95 \% \mathrm{CI}$ & OR & $95 \% \mathrm{CI}$ & OR & $95 \% \mathrm{CI}$ & OR & $95 \% \mathrm{CI}$ \\
\hline $\begin{array}{l}\text { Chalder Fatigue Questionnaire } \\
\text { score }>22\end{array}$ & 3.249 & $1.820-5.801^{*}$ & 2.583 & $1.230-5.133 *$ & 4.353 & $2.137-8.864 *$ & 3.267 & $1.739-6.135^{*}$ \\
\hline Medication intake & & & 0.725 & $0.341-1.540$ & & & & \\
\hline Seniority & & & 1.025 & $0.984-1.068$ & & & & \\
\hline $\begin{array}{l}\text { Main routes - national } \\
\text { vs. international (referent: } \\
\text { national) }\end{array}$ & & & 1.470 & $0.598-3.614$ & & & & \\
\hline Age & & & 0.986 & $0.945-1.029$ & & & & \\
\hline Smoking & & & 0.785 & $0.436-1.416$ & & & & \\
\hline Driving miles & & & & & 1.010 & $1.002-1.019^{*}$ & & \\
\hline Time spent driving & & & & & & & 1.141 & $1.024-1.270^{*}$ \\
\hline
\end{tabular}

\section{DISCUSSION}

There is a wide range of mechanisms probably underlying PD's fatigue, but a short self-administered questionnaire like the CFQ (which has well-known validity in assessing fatigue in the general population) could be useful in measuring fatigue in this group. According to our results, a CFS $>22$ indicates a risk of experiencing sudden-onset sleep at the wheel 4 times higher than for a $\mathrm{CFS} \leq 22$. This scale can be scored bimodally with columns representing $0,0,1$ and 1 and a range from 0 to 11 or, alternatively, it can be scored in Likert style 0, 1, 2 and 3 with a range from 0 to 33. In our study, a Likert scale was used with a range from 11 to 44 . According to Cella et al., a score of 29 on the fatigue scale can discriminate between patients (chronic fatigue syndrome sufferers) and nonpatients with $96 \%$ accuracy and a score above 30 discriminates in $100 \%$ of the cases [12]. In our sample, only 1 PD reached a score in the range that might lead to the suspicion of chronic fatigue syndrome.
In this regard, more than $40 \%$ of the 497 PDs recalled experiencing FAW at least once a month. This finding is consistent with, and adds to, those observed in other studies performed worldwide, with some variability according to the questionnaire used. In a group of Israeli truckers, more than $30 \%$ of the 160 drivers examined recalled FAW at least once, and $10.6 \%$ had fallen asleep while driving in the month before the interview [5]. Poor quality of sleep was also found in $46.3 \%$ of truck drivers studied to determine the prevalence and predictors of hypersomnolence among this category [13].

Our results indicate the following important risk factors for FAW: advanced age ( $>55$ years old, $\mathrm{OR}=4.91$ ), long distance trucking (traveling more than 40 thousand miles per year, OR $=1.86)$, obesity $(\mathrm{OR}=2.16)$ and self-reported fatigue $(\mathrm{CFS}>22, \mathrm{OR}=3.93)$. This means that we must focus our prevention efforts not only on young PDs, but also on older ones. Among drivers aged 50-69, the daily peak of sleep-related vehicle accidents is in the 


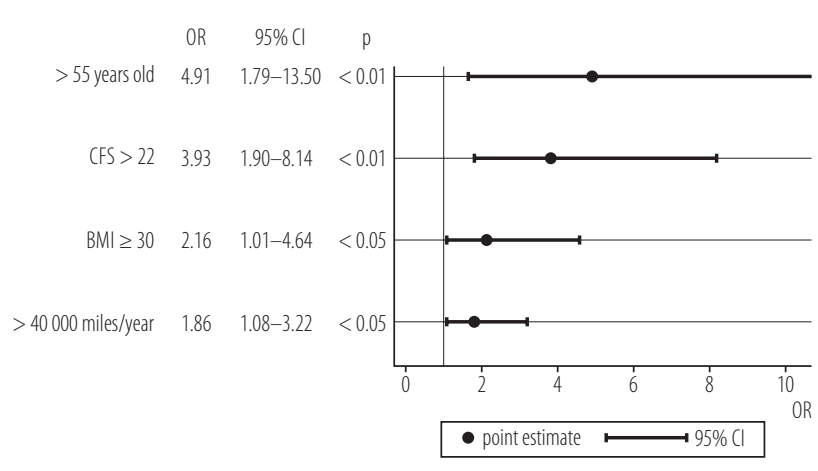

Abbreviations as in Tables 1-3.

Fig. 2. Factors associated with falling asleep at the wheel (FAW) among professional drivers and the relative odds ratio (OR)

early afternoon [14]. It is possible that these older PDs are more at risk of FAW while driving because they are more likely to drive at these times. It might also explain the ' $U$ '-shaped curve that indicates a higher risk of accident involvement for both younger and older drivers, as reported in a recent literature review [15]. Young age was not detected as a risk factor probably because less than $5 \%$ of our sample were $\leq 27$ years old.

Our results suggest the positive correlation between obesity and FAW as the main cause of this increased risk $(\mathrm{OR}=2.16)$, even if the obese PDs do not perceive an increased sensation of fatigue (measured with CFS). This is in agreement with the results of Moreno et al., which indicate a shorter sleep length in those PDs with greater BMI [16]. The present study was conducted investigating a large sample of PDs, most of whom, however, work for companies based in one Italian province only. The study population was selected from those doing the $\mathrm{CPC}$ and there was no randomization. This characteristic may appear as a limitation of the study. However, to our knowledge there are no local factors which impact or influence the application or interpretation of the results of this study on a national basis. The response rate was high (questionnaires not filled in were considered as refusals).

In our opinion, the main reason for this high response rate was because participants had fully understood the purpose of the study and they trusted the teacher of the course. The HiRis PD study was conducted to detect the most important predictive factors for accidents and near-miss accidents, therefore the analysis conducted in the present study must be considered as a secondary analysis. In addition, the results are based on cross-sectional data that include only a range of variables that might potentially determine an episode of sudden-onset sleep at the wheel (we do not record the role of working hours, sleep disorders or sleep loss). For these reasons, further studies are necessary to confirm the results of our analysis. Finally, the limitations of self-reported data are well known and clearly need to be considered in interpreting these results.

\section{CONCLUSIONS}

In conclusion, the results of this study show that fatigue and sudden-onset sleep at the wheel were prevalent in Italian PDs. Several significant correlated risk factors were identified both on the individual and occupational level. The results highlighted in this study might also provide input for new programmes for health promotion in the workplace.

\section{ACKNOWLEDGMENTS}

The authors express their thanks to "Federazione Autotrasportatori Italiani associazione provinciale di Cuneo", and to the "C.S.G. Consorzio Scuole Guida della provincia di Cuneo", particularly to the Autoscuola Dho di Brondello Livio e Musso Ivano Snc.

\section{REFERENCES}

1. Sagaspe P, Taillard J, Bayon V, Lagarde E, Moore N, Boussuge J, et al. Sleepiness, near-misses and driving accidents among a representative population of French drivers. J Sleep Res. 2010;19(4):578-84, http://dx.doi.org/10.1111/j.13 65-2869.2009.00818.x. 
2. Connor J, Norton R, Ameratunga S, Robinson E, Civil I, Dunn R, et al. Driver sleepiness and risk of serious injury to car occupants: Population based case control study. BMJ. 2002;324(7346):1125.

3. Horne J, Reyner L. Vehicle accidents related to sleep: A review. Occup Environ Med. 1999;56(5):289-94, http://dx.doi. org/10.1136/oem.56.5.289.

4. Perttula P, Ojala T, Kuosma E. Factors in the fatigue of heavy vehicle drivers. Psychol Rep. 2011;108(2):507-14, http:// dx.doi.org/10.2466/06.13.22.PR0.108.2.507-514.

5. Sabbagh-Ehrlich S, Friedman L, Richter ED. Working conditions and fatigue in professional truck drivers at Israeli ports. Inj Prev. 2005;11(2):110-4, http://dx.doi.org/10.1136/ ip.2004.007682.

6. Rosso GL, Zanelli R, Corino P, Bruno S. [Prevention of road accidents in the road haulage field]. G Ital Med Lav Ergon. 2007;29(3 Suppl):321-2. Italian.

7. Rosso GL, Zanelli R, Bruno S, Feola M, Bobbio M. [Professional driving and safety, a target for occupational medicine]. Med Lav. 2007;98(5):355-73. Italian.

8. Reyner LA, Horne JA. Falling asleep whilst driving: Are drivers aware of prior sleepiness? Int J Legal Med. 1998;111(3):120-3, http://dx.doi.org/10.1007/s004140050131.

9. Chalder T, Berelowitz G, Pawlikowska T, Watts L, Wessely S, Wright D, et al. Development of a fatigue scale. J Psychosom Res. 1993;37(2):147-53, http://dx.doi.org/10.1016/ 0022-3999(93)90081-P.
10. Saunders JB, Aasland OG, Babor TF, de la Fuente JR, Grant M. Development of the Alcohol Use Disorders Identification Test (AUDIT): WHO collaborative project on early detection of persons with harmful alcohol consumption-II. Addiction. 1993;88(6):791-804.

11. Rosso GL, Perotto M, Feola M, Caramella M. Workplace drug testing and alcohol policy in Italy, there is still a long way to go. Drug Test Anal. 2014;6(9):893-7, http://dx.doi. org/10.1002/dta.1569.

12. Cella M, Chalder T. Measuring fatigue in clinical and community settings. J Psychosom Res. 2010;69(1):17-22, http:// dx.doi.org/10.1016/j.jpsychores.2009.10.007.

13. de Pinho RS, da Silva-Júnior FP, Bastos JP, Maia WS, de Mello MT, de Bruin VM, et al. Hypersomnolence and accidents in truck drivers: A cross-sectional study. Chronobiol Int. 2006;23(5):963-71, http://dx.doi.org/10.1080/07420 520600920759 .

14. Horne JA, Reyner LA. Driver sleepiness. J Sleep Res. 1995;4(S2):23-9, http://dx.doi.org/10.1111/j.1365-2869. 1995.tb00222.x.

15. Duke J, Guest M, Boggess M. Age-related safety in professional heavy vehicle drivers: A literature review. Accid Anal Prev. 2010;42(2):364-71, http://dx.doi.org/10.1016/j.aap.20 09.09.026.

16. Moreno CR, Louzada FM, Teixeira LR, Borges F, LorenziFilho G. Short sleep is associated with obesity among truck drivers. Chronobiol Int. 2006;23(5):963-71.

This work is available in Open Access model and licensed under a Creative Commons Attribution-NonCommercial 3.0 Poland License - http://creativecommons.org/ licenses/by-nc/3.0/pl/deed.en. 